\title{
An Overview of Colorectal Cancer Screening
}

\section{Bhagat $\mathbf{V}^{*}$ and Wanebo $\mathrm{H}$}

Roger Williams Medical Center, USA

"Corresponding author: Bhagat V, Roger Williams Medical Center, Clinical Research Office, 825 Chalkstone Avenue, Prior 1, Providence, USA, Tel: 2013444901; Email: vbhagat15@gmail.com

Received date: September 30, 2015; Accepted date: October 29, 2015, 2015; Published date: October 30, 2015

Copyright: (2015 Bhagat V, et al. This is an open-access article distributed under the terms of the Creative Commons Attribution License, which permits unrestricted use, distribution, and reproduction in any medium, provided the original author and source are credited.

Keywords: Colorectal cancer; Crohn's disease; Ulcerative colitis

\section{Introduction}

Colorectal cancer (CRC) is the third most common cancer in both men and women. It is the second leading cause of cancer death for men and women combined. About 93,090 cases of colon and 39,610 rectal cancers are thought to be diagnosed in 2015. It has been estimated that about 49,700 deaths will be from CRC in 2015 .

Risk factors associated with CRC include history of inflammatory bowel disease (i.e., Crohn's disease or ulcerative colitis), diabetes mellitus type II, obesity, lack of physical activity, increasing age, moderate to heavy alcohol use, smoking, large consumption of red meat, decreased calcium intake, and decreased intake of fibre, fruits and vegetables. Family history or personal history of CRC and polyps is another important risk factor. There are also certain genetic conditions such as Lynch syndrome also known as hereditary nonpolyposis colorectal cancer (HNPCC) along with familial adenomatous polyposis that are associated with an increased risk of CRC [1].

Screening and removal of premalignant adenomas can reduce the incidence of cancer and cancer deaths. CRC usually arises from colorectal adenomas which progress from early to advanced to invasive cancer. A German epidemiological study showed that advanced adenomas progress to CRC and strongly increases with age. For women, in the age group of 55-59 the transition rate of adenomas to CRC of $2.6 \%$ increases to $5.6 \%$ in the age group of women greater than 80 . For men, the annual transition rate from advanced adenoma to CRC increases from $2.6 \%$ in age group $55-59$ to $5.1 \%$ in men greater than the age of 80 [2].

Over the years, incidence rates for CRC have been decreasing. From 2007 to 2011 , incidence rates have decreased by $4.3 \%$ per year for those above the age of 50 . Incidence rates have increased by $1.8 \%$ for adults younger than 50 years of age. The overall death rate has decreased by $2.5 \%$ per year during this time period. It seems as though these declining incidences rates are likely due to more knowledge about the risk factors associated with CRC along with improvements in screening [1].

There are many options available for screening to prevent CRC. In this review, we will discuss various strategies for screening CRC from noninvasive blood tests to endoscopy to different imaging modalities.

\section{Fecal Occult Blood Test (FOBT)}

There are two commonly used types of stool blood tests: guaiac fecal occult blood test (gFOBT) and fecal immunochemical test (FIT). Fecal occult blood tests (FOBT) rely on the presence of a bleeding CRC or an adenoma. gFOBT detects blood in the stool through the activation of peroxidase activity. Generally for the gFOBT there are three collections of the sample from consecutive bowel movements at home. Collection of three samples helps increase sensitivity of the test $[3,4]$. There are also a few food restrictions patients should be wary of when using a gFOBT. Patients should avoid aspirin, along with other non-steroidal anti-inflammatory drugs for 7 days. Vitamin C, along with red meat, poultry and fish should also be stopped 3 days prior to the exam to prevent false positives and negatives $[4,5]$.

Advantages of this test include that the test can be easily performed at home without any serious complications. If a positive test result were to occur, patient would need to have a colonoscopy. The sensitivity is variable for CRC screening with reported figures varying from about 13 to $64 \%$ and about 11 to $41 \%$ for advanced adenomas. Specificity for CRC screening is high and ranges from about 91 to $95 \%$ [6-9]. A Cochrane review consisting of more than 320,000 people demonstrated that participants allocated to screening had a $16 \%$ reduction in the relative risk of death from CRC, or 0.1 to 0.2 fewer colorectal cancer deaths per 1,000 patient-years $[6,10]$.

\section{Immunochemical Fecal Occult Blood Tests (FIT)}

FIT is able to detect human globin in stool by means of an immunochemical reaction. FIT is able to quantify actual hemoglobin concentration in stool $[9,11,12]$. In comparison to gFOBT, FIT does not have any dietary restrictions. In addition, there is no need to stop anticoagulants or aspirin prior to this test. The test is processed in an automated lab and only one measurement is needed versus three samples which are needed with the gFOBT.

Studies have shown that the sensitivity of FIT ranges from 47.1 to $100 \%$ and the specificity ranges from 88.2 to $97.1 \%$ [13-21]. In two Dutch population-based studies it was found that FIT detected advanced neoplasias three times more frequently than gFOBT [22,23]. It was seen that with gFOBT there were 6 subjects with advanced neoplasias per 1,000 screened whereas FIT, when using a cut-off of 50 ng hemoglobin per milliliter found 21 subjects per 1,000 screened. The study also showed that the distribution between true positives and false positives was the same with FIT and gFOBT [24].

In a Japanese study consisting of 22,666 participants who underwent colonoscopy and FIT it was found that neoplasia was seen in $36.5 \%$ (449 of 1237) of the FOBT positive patients and in $18.8 \%$ (3876 of 20,574) of the FOBT negative patients. This demonstrated that patients with a positive FIT had an increased risk for neoplasia as opposed to those with a negative FIT (relative risk, 1.9; 95\% confidence interval, 1.8-2.1). The study showed that the sensitivity of FIT was $27.1 \%$ for advanced neoplasia and $65.8 \%$ for cancer. FIT was also found to be less sensitive at detecting advanced neoplasia located in the proximal versus in the distal colon. This study demonstrated that the difference in sensitivity in the proximal and distal colon was seen for adenomas 10mm or larger and CRC of Dukes' stages C or D [25]. 


\section{(10.417/2157-2518.1000243}

Page 2 of 6

\section{Flexible Sigmoidoscopy (FSIG)}

This technique utilizes a flexible endoscopy to view images of 40 to $60 \mathrm{~cm}$ of the distal colon. Cleansing of the bowel is best achieved with a single phosphate enema that can be administered at home. This procedure can be performed without any sedation. This intervention allows for small polyps up to $9 \quad \mathrm{~mm}$ in diameter to be removed if needed [26]. The exam usually lasts 10-20 minutes but can take longer if a polyp is found. Common adverse effects associated with FSIG include nausea, fainting, dizziness, with the most common being bleeding [27-30]. Bleeding was seen in 8-306 per 10,000 screened $[27,30]$. Inflammation and bleeding requiring hospitalization was seen in 3-8 per 10,000 screened [27-29].

Three large studies, British Flex Sig Trial, Italian Score trial, and US PLCO (The Prostate, Lung, Colorectal and Ovarian) trial demonstrated that sigmoidoscopy as a screening tool lead to a $21-23 \%$ reduction in overall incidence of CRC after a followup of 11 years [26,29,31-33]. There was a reduction in the incidence of CRC in the distal colon to about $24-36 \%$ versus no reduction seen in the incidence of proximal CRC [26,33]. The Norwegian NORCCAP (Norwegian Colorectal Cancer Prevention) trial of the 4 major studies did not show a reduction in incidence of CRC but this may be due to a short follow up period of about 7 years. However, these four major trials have shown that FSIG decreases the incidence rates of CRC and also leads to a two-fold greater reduction of CRC mortality than biennial gFOBT screening. A 5 year-interval is recommended for normal FSIG exams [33].

\section{Colonoscopy}

Colonoscopy is the gold standard for screening as it allows for examination of the entire colon with the ability to remove any possible neoplasias [26,34]. Colonoscopy is an endoscopic technique utilizing a flexible, regular forward-viewing video colonoscopy that can view the entire colon. The bowel prep usually consists of a liquid diet at least one day prior, followed by a complete bowel lavage with oral laxatives. Accuracy of screening with a colonoscopy is dependent on proper bowel preparation $[4,35]$. It is usually performed with administration of I.V. benzodiazepine with or without an analgesic and sometimes with anesthesia.

In the National Polyp Study, a case-control done in the USA showed that adenoma removal with colonoscopy and proper surveillance during the followup period decreased the incidence of CRC rates by 76-90\%. In addition, it prevented CRC mortality within the following 10 years $[26,70,71]$. However, these results have not been reproduced in community practice. In a Canadian population study it was seen that colonoscopy screening reduced mortality caused by distal CRC by 47-67\% however it had no effect on mortality for proximal CRC $[26,36,37]$.

Studies have shown that endoscopists miss about $2 \%$ of adenomas $>1 \mathrm{~cm}$ to about $26 \%$ of adenomas $<5 \mathrm{~mm}$ in diameter $[26,38,39]$. Some studies have shown a colonoscopy miss rate of $6-12 \%$ for adenomas $>10 \mathrm{~mm}[4,40]$. Another study had shown that about $10 \%$ of neoplastic polyps are not completely removed [26,41]. Therefore, an effective colonoscopy is dependent on proper training, effective documentation, a clean bowel to allow for a full examination up to the cecum with adequate viewing of the mucosa, and the ability to remove polyps to send for pathological examination [4].
Advantages of the colonoscopy include being able to view the entire colon, detecting and removing any adenomas. Limitations of the test include the bowel preparation which should entail proper cleansing of the bowel. It is an invasive procedure with the risk of postpolypectomy bleeding and perforation which account for rates of about 0.1 to $0.3 \%$ $[9,42,43]$. The most common of the two is postpolypectomy bleeding and the chances increases with large polyps and location of the proximal colon. Other adverse effects include hypotension, arrhythmias, oxygen desaturation which account for about half of all adverse events and are usually secondary to sedation [4,44]. Current recommendations state that screening with colonoscopy every 10 years starting at the age of 50 if there are no other reasons to screen earlier is acceptable.

\section{CT Colonography (CTC)}

CT Colonography (CTC) which is also called virtual colonoscopy is an imaging modality that has been shown to be comparable to a colonoscopy in examining the entire colon and detecting clinically significant polyps and CRC [45-49]. It is considered to be less invasive than a colonoscopy $[9,35,50]$. In preparation for the test, patients consume a standard low-volume bowel preparation such as magnesium citrate with bisacodyl or polyethylene glycol bowel preparation alone. Tagging of colonic stool and fluid is done with $2 \%$ barium sulfate and diatrizoate respectively. Prior to CT imaging, a small rectal catheter is placed in the rectum and carbon dioxide is insufflated. CT images are acquired in $2 \mathrm{D}$ and $3 \mathrm{D}$ to determine size and location of polyps. There is no need for any I.V. sedation or analgesia [51-53].

The risk for colonic perforation compared with a colonoscopy is as low as $0.005 \%$ for asymptomatic patients [54] and up to $0.06 \%$ for symptomatic patients [55]. Another limitation is the risk posed by exposure to radiation.

The Imaging Network National CT Colonography trial consisting of 2,500 patients showed that accuracy of colonoscopy and CTC was comparable. Studies have shown a sensitivity of $89 \%$ for adenomas greater than $5 \mathrm{~mm}[56,57]$. The sensitivity was higher for invasive adenoma at $96 \%$ [58]. One study demonstrated that lesions $>6 \mathrm{~mm}$ at a specificity of $84.5 \%$ which increased to $97.4 \%$ for lesions $>1 \mathrm{~cm}$ $[4,56,59]$.

An adequate CTC is dependent on good intestinal preparation, adequate insufflation of the colon, and proper training of technicians acquiring images and physicians interpreting $2 \mathrm{D}$ and $3 \mathrm{D}$ images of the colon $[4,59]$. Currently, all patients with one or more polyps $>10 \mathrm{~mm}$ or 3 or more polyps $>6 \mathrm{~mm}$ are advised to obtain a colonoscopy [60]. Screening should commence at the age of 50. There is not enough evidence to suggest when follow up should be obtained with a negative CTC. At this time, recommendation is to repeat the test every 5 years.

\section{MR Colonography (MRC)}

Another method is obtaining an magnetic resonance imaging of the colon. This technique similar to the CTC allows for evaluation of the entire colon. MR Colonography (MRC) does not involve the use of ionizing radiation which is one reason why it may be favored over CTC. However, it is likely a contrast agent will be unitized for both CTC and MRC [9,61]. In one meta-analysis the sensitivity of MRC was $100 \%$ in detecting CRC. When polyps were greater than $10 \mathrm{~mm}$ in size the sensitivity was $88 \%$ and specificity was $99 \%[9,61]$. In a meta- 
analysis comparing CTC with MRC it was found that sensitivity and specificity was $95 \%$ for both MRC and CTC $[45,62,63]$.

\section{Double-Contrast Barium Enema (DCBE)}

The first radiological test to examine the entire colon was the double-contrast barium enema (DCBE). Prior to this test, a laxative should be given. During the test, the entire colon is coated with barium sulfate and air is introduced through a flexible catheter into the rectum. X-rays are taken while changing the position of the patient to assess for the presence of lesions. This procedure takes about 30 to 45 min. Studies have shown that sensitivity ranges from 50 to $80 \%$ for polyps smaller than $1 \mathrm{~cm}, 70$ to $90 \%$ for polyps greater than $1 \mathrm{~cm}$, and from 55 to $85 \%$ for Dukes Stage A and B [64,65]. The quality of the examination is affected by adequate bowel preparation, proper barium distribution throughout the colon, patient being able to change positions and the experience of the interpreter. Patient should undergo colonoscopy if the examination were to show a polyp of greater than $6 \mathrm{~mm}$. Another limitation are the side effects which include bloating and cramps. The risk of perforation is low with rates showing 1 in 25,000 for DCBE compared to 1 in 1,000 and 2,000 colonoscopies $[4,66]$. Patients also seem to experience more discomfort with this exam in comparison with FOBT, FSIG, and colonoscopy $[4,66]$.

\section{Stool DNA}

A new technique is the use of detecting DNA, RNA and protein biomarkers in stool samples. CRC is associated with mutations in genes such as APC, K-ras, and p53. Cells from the cancer and polyps can be found in the feces. The test consists of multi-marker panel of numerous mutations since there is not one single DNA mutation present in cells. For instance, the first version of the test included mutations in APC, P53, BAT-26 and K-ras [4,67-69]. The test necessitates a stool sample that is at least $30 \mathrm{~g}$ in weight.

Several studies have shown that sensitivity ranged from 52 to $91 \%$ and specificity ranged from 93 to $97 \%$ [4,69-75]. In a study comparing sDNA, gFOBT, and colonoscopy with 2,507 people with average risk it was found that sDNA test had a greater sensitivity of $52 \%$ in comparison to $13 \%$ for gFOBT. In addition, this study showed that sDNA had a lower sensitivity of $15.1 \%$ when detecting advanced adenomas (tubular adenoma $>1 \mathrm{~cm}$, a villous adenoma, or an adenoma with high grade dysplasia). The sensitivity for gFOBT for advanced adenomas was much lower at $10.7 \%[4,59,70]$.

Advantage of this test is that it is not invasive and can easily be performed in the privacy of one's home. However, this test is very expensive and if cancer is suspected the patient will need to undergo a colonoscopy. This test poses an option for those who are deterred by endoscopy as means for screening [71-73].

\section{FDG-PET Scan}

18F-Flurodeoxyglucose positron emission tomography (FDG-PET) is often used to detect recurrence of CRC. FDG-PET makes use of a glucose analog FDG which is labeled with the cyclotron-produced, positron-emitting radioisotope fluorine-18. In malignancy, there is an increased uptake of glucose in comparison with the surrounding normal tissue. The focal increased FDG uptake allows one to identify the malignant tumors [74-76]. It should be noted that this uptake is nonspecific and is also seen in other inflammatory conditions with increased metabolism. Patients are asked to fast 6 hours prior to imaging. A dose of intravenous FDG is given and scanning is done after 45 minutes thereafter. Images are acquired with a tomograph in axial, coronal and sagittal planes [77].

Studies have shown that FDG-PET imaging can detect primary carcinomas and premalignant lesions of the large bowel [77-81]. The size of the lesion and grade of dysplasia plays a role in the sensitivity. The sensitivity is about $72 \%$ for a tumor larger than $1 \mathrm{~cm}$ and is about $33 \%$ for low grade lesions and $76 \%$ for high grade lesions [77,81]. A colonoscopy is warranted when focally increased uptake of FDG is seen in the colon. There are few studies that discuss the usefulness of FDG-PET scanning in the initial staging of CRC. The sensitivity of detection of nodal metastasis is poor and not significantly different from CT imaging. Thus, the use of this imaging modality in preoperative staging of CRC can be used but does have a significant impact on clinical management $[77,82]$. Other limitations of PET scan include movement of respirations and physiological uptake of $18 \mathrm{~F}$ FDG into the liver and colon which can reduce the contrast resolution of the PET scan [83]. Studies have shown that FDG-PET in conjunction with CT in preoperative planning of patients with hepatic metastases has allowed for identification of additional extrahepatic disease sites in about $11-23 \%$ of cases [84].

\section{Discussion}

Screening can detect polyps and reduce the incidence of CRC. Current guidelines recommend screening to begin at the age of 50 years for those with average risk. Colonoscopy should be recommended for patients with a first-degree relative with either CRC or adenomatous polyps before the age of 60 or in 2 or more relatives at any age. Screening should begin at the age of 40 for such patients or 10 years prior to the youngest case of CRC in the family $[59,64]$.

As discussed there are many different modalities available for the purpose of screening.

The choice depends on patient's preferences for convenience, time, and money. Each test has different advantages and disadvantages.

Current recommendations state that FOBT should be done every 2 years, FIT should be done every 2 years, colonoscopy should be done every 10 years, FSIG should be done every 5 years, DCBE should be done every 5 years, and CTC should be done every 5 years. There is not enough evidence to suggest the interval follow up for sDNA.

Screening can save costs. Chemotherapy costs have gone up throughout the years and thus screening and preventing advanced CRC can prevent costs associated with cancer diagnosis. One study found that when compared with no screening, the savings from treatment by preventing CRC and deaths secondary to CRC doubled with the use of new chemotherapy agents $[4,85]$.

Screening can reduce rates of mortality and morbidity from CRC however the rates of screening continue to be low. National CRC screening rates are about $45 \%$ which is much lower than screening rates for prostate, cervical and breast cancer $[4,86]$. These rates may be low due to lack of access to care, fear of screening tests, inadequate understanding of cancer risks and screening, lack of specialists, problems with referrals, etc. This seems to be a world-wide issue. In Europe, less than $25 \%$ of the population is screened [26,36]. Screening in the US tends to start at the primary care setting. In order to effectively increase screening rates, we will have to explain the importance of screening and provide patients with different options for screening. 


\section{References}

1. American Cancer Society. Cancer Facts \& Figures 2015 Atlanta, Ga: American Cancer Society; 2015.

2. Brenner H, Hoffmeister M, Stegmaier C, Brenner G, Altenhofen L, et al. (2007) Risk of progression of advanced adenomas to colorectal cancer by age and sex: estimates based on 840,149 screening colonoscopies. Gut 56: 1585-1589.

3. Liberman DA, Weiss DG, Veterans Affairs Cooperative Study Group 380 (2001) One-time screening for colorectal cancer screening with combined fecal occult blood testing and examination of the distal colon. $\mathrm{N}$ England J Med 345: 555-560.

4. Labianca R, Merelli B (2010) Screening and diagnosis for colorectal cancer: present and future. Tumori 96: 889-901.

5. Ransohoff DF , Lang CA (1997) Screening for colorectal cancer with the fecal occult blood test: a background paper. American College of Physicians. Ann Intern Med 126: 811-822.

6. Hewtison P, Glasziou P, Irwig L, Towler B, Watson E (2007) Screening for colorectal cancer using the faecal occult blood test, Hemoccult. Cochrane Data base Syst Rev 24: CD001216.

7. Allison JE, Sakoda LC, Levin TR, Tucker JP, Tekawa IS, et al. (2007) Screening for colorectal neoplasms with new fecal occult blood tests: update on performance characteristics. J Natl Cancer Inst 99: 1462-1470.

8. Imperiale TF, Ransohoff DF, Itzkowitz SH, Turnbull BA, Ross ME; Colorectal Cancer Study Group (2004) Fecal DNA versus fecal occult blood for colorectal-cancer screening in an average-risk population. $\mathrm{N}$ Engl J Med 351: 2704-2714.

9. de Wijkerslooth TR, Bossuyt PM, Dekker E (2011) Strategies in screening for colon carcinoma. Neth J Med 69: 112-119.

10. Kumaravel V, Hayden SP, Hall GS, Burke CA (2011) New fecal occult blood tests may improve adherence and mortality rates. Cleve Clin J Med 78: 515-520.

11. Hol L, Wilschut JA, van Ballegooijen M, van Vuuren AJ, van der Valk H, et al. (2009) Screening for colorectal cancer: random comparison of guaiac and immunochemical faecal occult blood testing at different cutoff levels. Br J Cancer 100: 1103-1110.

12. Rossum LG, van Rijn AF, Laheij RJ, van Oijen MG, Focketns P, et al. (2009) Cut off value determines the performance of a semi-quantitative immunochemical fecal occult blood test in colorectal cancer screening program. Br J Cancer 101: 1274-1281.

13. St John DJ, Young GP, Alexeyeff MA, Deacon MC, Cuthbertson AM, et al. (1993) Evaluation of new occult blood tests for detection of colorectal neoplasia. Gastroenterology 104: 1661-1668.

14. Allison JE, Tekawa IS, Ransom LJ, Adrain AL (1996) A comparison of fecal occult-blood tests for colorectal-cancer screening. N Engl J Med 334: 155-159.

15. Wong WM, Lam SK, Cheung KL, Tong TS, Rozen P, et al. (2003) Evaluation of an automated immunochemical fecal occult blood test for colorectal neoplasia detection in a Chinese population. Cancer 97: 2420-2424.

16. Rozen P, Knaani J, Samuel Z (1997) Performance characteristics and comparison of two immunochemical and two guaiac fecal occult blood screening tests for colorectal neoplasia. Dig Dis Sci 42: 2064-2071.

17. Nakama H, Kamijo N, Miyata K, Abdul Fattah AS, Zhang B, et al. (1998) Sensitivity and specificity of several immunochemical tests for colorectal cancer. Hepatogastroenterology 45: 1579-1582.

18. Nakama H, Zhang B, Fattah AS (2000) A cost-effective analysis of the optimum number of stool specimens collected for immunochemical occult blood screening for colorectal cancer. Eur J Cancer 36: 647-650.

19. Nakama H, Yamamoto M, Kamijo N, Li T, Wei N, et al. (1999) Colonoscopic evaluation of immunochemical fecal occult blood test for detection of colorectal neoplasia. Hepatogastroenterology 46: 228-231.

20. Wong BC, Wong WM, Cheung KL, Tong TS, Rozen P, et al. (2003) A sensitive guaiac fecal occult blood test is less useful than an immunochemical test for colorectal cancer screening in a Chinese population. Aliment Phamacolo Ther 18: 941-946.
21. Greenberg PD, Bertario L, Gnauck R, Kronborg O, Hardcastle JD, et al. (2000) A prospective multicenter evaluation of new fecal occult blood tests in patients undergoing colonoscopy. Am J Gastroenterol 95: 1331-1338.

22. Hol L, van Leerdam ME, van Ballegooijen M, van Vuuren AJ, van Dekken $\mathrm{H}$, et al. (2010) Screening for colorectal cancer: randomised trial comparing guaiac-based and immunochemical faecal occult blood testing and flexible sigmoidoscopy. Gut 59: 62-68.

23. van Rossum LG, van Rijn AF, Laheij RJ, van Oijen MG, Fockens P, et al. (2008) Random comparison of guaiac and immunochemical fecal occult blood tests for colorectal cancer in a screening population. Gastroenterology 135: 82-90.

24. Hol L, Wilschut JA, van Ballegooijen M, van Vuuren AJ, van der Valk H, et al. (2009) Screening for colorectal cancer: random comparison of guaiac and immunochemical faecal occult blood testing at different cutoff levels. Br J Cancer 100: 1103-1110.

25. Morikawa T, Kato J, Yamaji Y, Wada R, Mitsushima T, et al. (2005) A comparison of the immunochemical fecal occult blood test and total colonoscopy in the asymptomatic population. Gastroenterology 129: 422-428.

26. Kuipers EJ, Rösch T, Bretthauer M (2013) Colorectal cancer screening-optimizing current strategies and new directions. Nat Rev Clin Oncol 10: 130-142.

27. Littlejohn C, Hilton S, Macfarlane GJ, Phull P (2012) Systematic review and meta-analysis of the evidence for flexible sigmoidoscopy as a screening method for the prevention of colorectal cancer. Br J Surg 99: 1488-1500.

28. Atkin WS, Hart A, Edwards R, McIntyre P, Aubrey R, et al. (1998) Uptake, yield of neoplasia, and adverse effects of flexible sigmoidoscopy screening. Gut 42: 560-565.

29. Segnan N, Senore C, Andreoni B, Aste H, Bonelli L, et al. (2002) Baseline findings of the Italian multicenter randomized controlled trial of "onceonly sigmoidoscopy"--SCORE. J Natl Cancer Inst 94: 1763-1772.

30. Brevinge H, Lindholm E, Buntzen S, Kewenter J (1997) Screening for colorectal neoplasia with faecal occult blood testing compared with flexible sigmoidoscopy directly in a 55-56 years' old population. Int J Colorectal Dis 12: 291-295.

31. Atkin WS, Edwards R, Kralj-Hans I, Wooldrage K, Hart AR, et al. (2010) Once-only flexible sigmoidoscopy screening in prevention of colorectal cancer: a multicentre randomised controlled trial. Lancet 375: 1624-1633.

32. Schoen RE, Pinsky PF, Weissfeld JL, Yokochi LA, Church T, et al. (2012) Colorectal-cancer incidence and mortality with screening flexible sigmoidoscopy. N Engl J Med 366: 2345-2357.

33. Winawer S, Fletcher R, Rex D, Bond J, Burt R, et al. (2003) Gastrointestinal Consortium Panel: Colorectal cancer screening and surveillance: clinical guidelines and rationale- update based on new evidence. Gastroenterology 124: 544-560.

34. Valori R, Rey JF, Atkin WS, Bretthauer M, Senore C, et al. (2012) European guidelines for quality assurance in colorectal cancer screening and diagnosis. First edition quality assurance in endoscopy in colorectal cancer screening and diagnosis. Endoscopy 3: SE88-SE105.

35. Rex DK, Imperiale TF, Latinovich DR, Bratcher LL (2002) Impact of bowel preparation on efficiency and cost of colonoscopy. Am J Gastroenterol 97: 1696-1700.

36. Winawer SJ, Zauber AG, Ho MN, O'Brien MJ, Gottlieb LS, et al. (1993) Prevention of colorectal cancer by colonoscopic polypectomy. The National Polyp Stuyd Workgroup. N Engl J Med. 329, 1977-1981.

37. Zauber AG, Winawer SJ, O'Brien MJ, Lansdorp-Vogelaar I, van Ballegooijen M, et al. (2012) Colonoscopic polypectomy and long-term prevention of colorectal-cancer deaths. N Engl J Med 366: 687-696.

38. van Rijn JC, Reitsma JB, Stoker J, Bossuyt PM, van Deventer SJ, et al. (2006) Polyp miss rate determined by tandem colonoscopy: a systematic review. Am J Gastroenterol 101: 343-350.

39. Ramsoekh D, Haringsma J, Poley JW, van Putten P, van Dekken H, et al. (2010) A back-to-back comparison of white light video endoscopy with 
autofluorescence endoscopy for adenoma detection in high-risk subjects. Gut 59: 785-793.

40. Rex DK, Cutler CS, Lemmel GT, Rahmani EY, Clark DW, et al. (1997) Colonoscopic miss rates of adenomas determined by back-to-back colonoscopies. Gastroenterology 112: 24-28.

41. Pohl H, Srivastava A, Bensen SP, Anderson P, Rothstein RI, et al. (2013) Incomplete polyp resection during colonoscopy-results of the complete adenoma resection (CARE) study. Gastroenterology 144: 74-80.

42. Nelson DB, McQuaid KR, Bond JH, Lieberman DA, Weiss DG, et al. (2002) Procedural success and complications of large-scale screening colonoscopy. Gastrointest Endosc 55: 307-314.

43. Regula J, Rupinski M, Kraszewska E, Polkowski M, Pachlewski J, et al. (2006) Colonoscopy in colorectal-cancer screening for detection of advanced neoplasia. N Engl J Med 355: 1863-1872.

44. Rex DK, Bond JH, Winawer S, Levin TR, Burt RW, et al. (2002) US MultiSociety Task Force on colorectal cancer: Quality in the technical performance of colonoscopy and the continuous quality improvement process for colonoscopy: recommendations of the US Multi-Society Task force on Colorectal Cancer. Am J Gastroenterol 97: 1296-1308.

45. He Q, Rao T, Guan YS (2014) Virtual gastrointestinal colonoscopy in combination with large bowel endoscopy: clinical application. World J Gastroenterol 20: 13820-13832.

46. Graser A, Stieber P, Nagel D, Schaefer C, Horst D, et al. (2009) Comparison of CT colonography, colonoscopy, sigmoidoscopy, and fecal occult blood tests for the detection of advanced adenomas in an average risk population. Gut 58: 241-248.

47. Johnson CD, Chen MH, Toledano AY, Heiken JP, Dachman A, et al. (2008) Accuracy of CT colonography for detection of large adenomas and cancers. N Engl J Med 359: 1207-1217.

48. Pickhardt PJ, Choi JR, Hwang I, Butler JA, Puckett ML, et al. (2003) Computed tomographic virtual colonoscopy to screen for colorectal neoplasia in asymptomatic adults. N Engl J Med 349: 2191-2200.

49. Regge D, Laudi C, Gatatola G, Della Monica P, Bonelli L, et al. (2009) Diagnostic accuracy of computed tomographic colonography for the detection of advanced neoplasia in individuals are increased risk of colorectal cancer. JAMA 301: x`2453-2461.

50. Takahashi Y, Tanaka H, Kinjo M, Sakumoto K (2005) Sedation-free colonoscopy. Dis Colon Rectum 48: 855-859.

51. Barret M, Boustiere C, Canard JM, Arpurt JP, Bernadrdini D, et al. (2013) Factors assoicated with adenoma detection rate and diagnosis of polyps and colorectal cancer during colonoscopy in France: results of a prospective, nationwide survey. PLos One 8: e68947.

52. Vining DJ, Gelfand DW(1994) Noninvasive colonoscopy using helical CT scanning. 3D reconstruction and virtual reality. Maui, Hawaii. Syllabus of the 23rd Annual Meeting Society of gastrointestinal radiologists, pp. 13-18.

53. Cash BD, Stamps K, McFarland EG, Spiegel AR, Wade SW (2013) Clinical use of CT colonography for colorectal cancer screening in military training facilities and potential impact on HEDIS measures. J Am Coll Radiol 10: 30-36.

54. Berrington de Gonzalez A, Kim KP, Yee J (2010) CT colonography: perforation rates and potential radiation risks. Gastrointest Endosc Clin N Am 20: 279-291.

55. Burling D, Halligan S, Slater A, Noakes MJ, Taylor SA (2006) Potentially serious adverse events at CT colonography in symptomatic patients: national survey of the United Kingdom. Radiology 239: 464-471.

56. Pickhardt PJ, Choi JR, Hwang I, Butler JA, Puckett ML, et al. (2003) Computed tomographic virtual colonoscopy to screen for colorectal neoplasia in asymptomatic adults. N Engl J Med 349: 2191-2200.

57. Ramos O Jr, Boguszewski CL, Teixeira S, De Bem R, Parolim B, et al. (2009) Performance of computed tomographic colonography for the screening of colorectal polyp in acromegalic patients: a prospective study. Arq Gastroenterol 46: 90-96.

58. Kim DH, Pickhardt PJ, Taylor AJ (2007) Characteristics of advanced adenomas detected at CT colonographic screening: implications for appropriate polyp size thresholds for polypectomy versus surveillance. AJR Am J Roentgenol 188: 940-944.

59. Levin B, Liberman DA, McFarland B, Smith RA, Brooks D, et al. (2008) Screening and Surveillance for the early detection of colorectal cancer and adenomatous polyps: A Joint Guideline from the American Cancer Society, The US Multi-society Task Force on Colorectal Cancer and the American College of Radiology. Gastroenterology 134: 1570-1595.

60. Doria-Rose VP, Newcomb PA, Levin TR (2005) Incomplete screening flexible sigmoidoscopy associated with female sex, age, and increased risk of colorectal cancer. Gut 54: 1273-1278.

61. van der Paardt MP, Zijta F, Stoker J (2010) MRI of the colon. Imaging Med 2: 195-209.

62. Zijta FM, Bipat S, Stoker J (2010) Magnetic resonance (MR) colonography in the detection of colorectal lesions: a systematic review of prospective studies. Eur Radiol 20: 1031-1046.

63. Purkayastha S, Athanasiou T, Tekkis PP, Constantinides V, Teare J, et al. (2007) Magnetic resonance colonography vs computed tomography colonography for the diagnosis of colorectal cancer: an indirect comparison. Colorectal Dis 9: 100-111.

64. Turgeon DK, Ruffin MT 4th (2014) Screening strategies for colorectal cancer in asymptomatic adults. Prim Care 41: 331-353.

65. Winawer SJ, Fletcher RH, Miller L, Godlee F, Stolar MH, et al. (1997) Colorectal cancer screening: clinical guidelines and rationale. Gastroenterology 112: 594-642.

66. Blakeborough A, Sheridan MB, Chapman AH (1997) Complications of barium enema examinations: a survey of UK Consultant Radiologists 1992 to 1994. Clin Radiol 52: 142-148.

67. Taylor SA, Halligan S, Saunders BP, Bassett P, Vance M, et al. (2003) Acceptance by patients of multidetector CT colonography compared with barium enema examinations, flexible sigmoidoscopy, and colonoscopy. AJR Am J Roentgenol 181: 913-921.

68. Whitney D, Skoletsky J, Moore K, Boynton K, Kann L, et al. (2004) Enhanced retrieval of DNA from human fecal samples results in improved performance of colorectal cancer screening test. J Mol Diagn 6: 386-395.

69. Olson J, Whitney DH, Durkee K, Shuber AP (2005) DNA stabilization is critical for maximizing performance of fecal DNA-based colorectal cancer tests. Diagn Mol Pathol 14: 183-191.

70. Imperiale TF, Ransohoff DF, Itzkowitz SH, Turnbull BA, Ross ME; Colorectal Cancer Study Group (2004) Fecal DNA versus fecal occult blood for colorectal-cancer screening in an average-risk population. N Engl J Med 351: 2704-2714.

71. Ahlquist DA, Skoletsky JE, Boynton KA, Harrington JJ, Mahoney DW, et al. (2000) Colorectal cancer screening by detection of altered human DNA in stool: feasibility of a multi-target assay panel. Gastroenterology 119: 1219-1227.

72. Calistri D, Rengucci C, Bocchini R, Saragoni L, Zoli W, et al. (2003) Fecal multiple molecular tests to detect colorectal cancer in stool. Clin Gastroenterol Hepatol 1: 377-383.

73. Tagore KS, Lawson MJ, Yucaitis JA, Gage R, Orr T, et al. (2003) Sensitivity and specificity of a stool DNA multitarget assay panel for the detection of advanced colorectal neoplasia. Clin Colorectal Cancer 3: 47-53.

74. Brand RE, Ross ME, Shuber AP (2004) Reproducibility of a multitarget stool-based DNA assay for colorectal cancer detection. Am J Gastroenterol 99: 1338-1341.

75. Syngal S, Stoffel E, Chung D, Willett C, Schoetz D, et al. (2006) Detection of stool DNA mutations before and after treatment of colorectal neoplasia. Cancer 106: 277-283.

76. Zealley IA, Skehan SJ, Rawlinson J, Coates G, Nahmias C, et al. (2001) Selection of patients for resection of hepatic metastases: improved detection of extrahepatic disease with FDG pet. Radiographics 21: S55-69. 
Citation: Bhagat V, Wanebo H (2015) An Overview of Colorectal Cancer Screening . J Carcinog Mutagene 6: 243. doi: $10.4172 / 2157-2518.1000243$

Page 6 of 6

77. Esteves FP, Schuster DM, Halkar RK (2006) Gastrointestinal tract malignancies and positron emission tomography: an overview. Semin Nucl Med 36: 169-181.

78. Friedlan S, Soetikno R, Carlisle M, Taur A, Kaltenbach T, et al. 18 Flurodeoxyglucose positron emission tomography has limited sensitivity for colonic adenoma and early stage colon cancer. Gastrointest Endosc 61: 395-400

79. Gutman F, Alberini JL, Wartski M, Vilain D, Le Stanc E, et al. (2005) Incidental colonic focal lesions detected by FDG PET/CT. AJR Am J Roentgenol 185: 495-500.

80. Kamel EM, Thumshirn M, Truninger K, Schiesser M, Fried M, et al. (2004) Significance of incidental 18F-FDG accumulations in the gastrointestinal tract in PET/CT: correlation with endoscopic and histopathologic results. J Nucl Med 45: 1804-1810.

81. von Kouwen MC, Nagengast FM, Jansen JB, Oyen WJ, Drenth JP, et al. (2005) 2-(18F)-fluoro-2-deoxy-D-glucose positron emission tomography detects clinical relevant adenomas of the colon: a prospective study. J Clin Oncol 23: 3713-3717.
82. Kantorová I, Lipská L, Bêlohlávek O, Visokai V, Trubaĉ M, et al. (2003) Routine (18)F-FDG PET preoperative staging of colorectal cancer: comparison with conventional staging and its impact on treatment decision making. J Nucl Med 44: 1784-1788.

83. Kalff V, Hicks RJ, Ware RE, Hogg A, Binns D, et al. (2002) The clinical impact of (18)F-FDG PET in patients with suspected or confirmed recurrence of colorectal cancer: a prospective study. J Nucl Med 43: 492-499.

84. Llamas-Elvira JM, Rodríguez-Fernández A, Gutiérrez-Sáinz J, GomezRio M, Bellon-Guardia M, et al. (2007) Fluorine-18 fluorodeoxyglucose $\mathrm{PET}$ in the preoperative staging of colorectal cancer. Eur J Nucl Med Mol Imaging 34: 859-867.

85. Lansdorp-Vogelaar I, van Ballegooijen M, Zauber AG, Habbema JD, Kuipers EJ (2009) Effect of rising chemotherapy costs on the cost savings of colorectal cancer screening. J Natl Cancer Inst 101: 1412-1422.

86. American Cancer Society: Cancer Prevention and Early detection Facts \& Figures 2007. 